\title{
As cidades e a classe criativa no Brasil: diferenças espaciais na distribuição de indivíduos qualificados nos municípios brasileiros
}

\author{
André Braz Golgher*
}

\begin{abstract}
Partindo da premissa de que estudos regionais devem incorporar aspectos econômicos e culturais conjuntamente e tendo como base empírica os indicadores propostos por Florida, são confeccionados vários indicadores relacionados à distribuição de indivíduos qualificados nos municípios brasileiros. Análises descritivas e a utilização da técnica multivariada de aglomerados mostram que alguns municípios destacam-se com os valores mais elevados para diversos dos indicadores, tais como: São Caetano do Sul (SP), Niterói (RJ) e Florianópolis (SC). Estudos econométricos indicam que municípios com maior população, que são capitais de estado, mais urbanizados, localizados nas regiões Sul, Sudeste ou Centro-Oeste e com maior participação dos setores secundário e terciário na economia tendem a ter maiores proporções de trabalhadores na economia criativa, ou maiores índices de qualificação. A hipótese de Florida, que propõe que locais com atmosfera mais vibrante também apresentam essa tendência, não foi corroborada por esses estudos.
\end{abstract}

Palavras-chave: Florida. Indicadores de qualificação.

\section{Introdução}

O desenvolvimento regional pode ser analisado a partir de diversas abordagens e perspectivas (NEARY, 2001; SCOTT, 2004), entre as quais inclui-se aquela que ressalta que os sistemas produtivos no capitalismo contemporâneo focam-se, cada vez mais, no processamento de informações e símbolos e em aspectos gerenciais para serviços culturais. Portanto, segundo essa perspectiva, estudos regionais deveriam incorporar aspectos econômicos e culturais conjuntamente. Assim, análises que tratam da performance produtiva espacial ou da produtividade e crescimento regionais deveriam ser abordadas a partir do estudo da relação entre esses dois aspectos, com a cooperação e síntese de estudos da geografia econômica e da geografia cultural (SCOTT, 2004).

Seguindo essa perspectiva, um importante fator em estudos sobre desenvolvimento e diversidade regionais seria a distribuição espacial de capital humano e de indivíduos criativos ${ }^{1}$ (FLORIDA, 2002a). Como destacado no livro de Jacobs (2001), as cidades são decisivas na atração, aglomeração e mobilização de pessoas criativas. $\mathrm{O}$ ponto-chave para $\mathrm{o}$ crescimento $\mathrm{e}$ desenvolvimento de cidades e de regiões seria o aumento na produtividade associado com a aglomeração de capital humano ou de pessoas qualificadas e criativas. Desta

\footnotetext{
* Doutor em Demografia, professor do Centro de Desenvolvimento e Planejamento Regional - Cedeplar/UFMG.

1 O termo é adotado segundo a descrição de Florida (2005). Indivíduos criativos são aqueles que se ocupam de atividades criativas, como definido pelo autor, o que será discutido posteriormente.
} 
maneira, a habilidade de um local em produzir e atrair pessoas criativas seria 0 fator central no desenvolvimento regional (FLORIDA, 2002a).

São muitos os fatores que aumentam ou diminuem a atratividade relativa de uma região em comparação às demais, sendo que os fatores econômicos são considerados os mais importantes (GOLGHER, 2004). Entre estes, destacam-se as diferenças de salários nas várias regiões, as possibilidades diferenciadas de obtenção de empregos, o custo variável de moradia e de vida, a maior presença de empregos na indústria, etc. Apesar do predomínio dos fatores econômicos na atratividade relativa regional, variáveis não-econômicas também são importantes, principalmente em países do Primeiro Mundo e para as camadas de maior renda e escolaridade em países em desenvolvimento. Estas variáveis não-pecuniárias apresentam importância cada vez maior na formação dos fluxos de migrantes qualificados. A busca por locais com mais amenidades urbanas, tais como aqueles que apresentam melhores condições climáticas, menores níveis de criminalidade, melhores oportunidades de lazer, menores níveis de poluição, menos congestionamento de tráfego, melhores condições de moradia, etc. (GOLGHER, 2004; FLORIDA, 2002b), seria um fator decisivo para pessoas qualificadas, criativas e com alta escolaridade.

Além dos fatores "tradicionais" mencionados, que tornam um local mais atraente para pessoas criativas e qualificadas, Florida (2002a) aponta outros que também seriam relevantes. Por exemplo, Florida (2002b) discute a importância de uma sociedade vibrante na atração de talentos. A hipótese do autor é que a presença de um grande contingente de pessoas que trabalham em atividades relacionadas ao entretenimento forma uma atmosfera favorável à atração de indivíduos talentosos e criativos, que, por sua vez, promovem atividades de grande valor agregado e indústrias de alta tecnologia.

Assim, atrair pessoas criativas e qualificadas seria a política mais eficaz de desenvolvimento regional. Regiões com melhores níveis de qualidade de vida, atividades culturais mais desenvolvidas, sociedade mais diversificada $^{2}$ e vida social mais vibrante apresentariam uma tendência a atrair pessoas qualificadas e criativas. Esse pool de capital humano seria o ponto principal para o desenvolvimento e crescimento regionais e o setor cultural seria decisivo na formação de pólos de desenvolvimento espacial (NEW ENGLAND COUNCIL, 2000).

Como discutido anteriormente, dada a importância da distribuição de capital humano para o desenvolvimento regional, este texto tem como principal objetivo fazer uma análise empírica sobre a distribuição de indivíduos qualificados nos municípios brasileiros. Para tanto, são confeccionados vários indicadores, alguns baseados na metodologia empregada em Florida (2002a, $2002 b$ e 2005), com a utilização dos microdados do Censo Demográfico de 2000. Esses são na ordem em que aparecem no texto: proporção de trabalhadores no setor criativo; índice de qualificação superior; índice de qualificação de pós-graduação; índice de qualificação técnica superior; índice de qualificação técnica de pós-graduação; índice síntese; índice de alta tecnologia bruto; índice de alta tecnologia relativo; e índice de entretenimento.

Tendo como base esses indicadores, foram feitos alguns estudos, como será detaIhado a seguir, que buscaram compreender como se distribuíam os indivíduos qualificados nos municípios brasileiros. Para tanto, esse artigo foi dividido em cinco partes, incluindo essa introdução. A seguinte apresenta uma análise descritiva desses diversos indicadores. Posteriormente, analisam-se os municípios mais populosos e aqueles com maior concentração de pessoas quali-

\footnotetext{
2 Florida também discute a importância de uma maior diversidade populacional na atração de talentos. Entretanto, o indicador proposto por esse autor para essa variável não foi confeccionado para municípios, devido ao pequeno tamanho da amostra da maioria deles na base de dados utilizada nas análises empíricas, que é o Censo Demográfico do Brasil de 2000.
} 
ficadas, a partir da técnica multivariada de aglomerados. O objetivo é classificar esses municípios com relação a algumas características, traçando um perfil de cada um deles. Depois disso, discutem-se os dados de alguns destes indicadores a partir de regressões múltiplas MQO, com o objetivo de determinar algumas das variáveis que explicam a heterogeneidade espacial da distribuição de indivíduos qualificados. Além disso, procura-se testar a hipótese de Florida, que sugere que sociedades mais vibrantes tendem a concentrar indivíduos mais qualificados. Por fim, são apresentadas as conclusões do trabalho.

\section{Análise descritiva dos dados para municípios no Brasil}

Como a fonte de dados utilizada Censo Demográfico de 2000 - possui uma amostra bastante grande, aproximadamente 20 milhões de observações para todo o país, podem ser confeccionados vários indicadores para municípios. Entretanto, para alguns deles, principalmente para municípios com pequena população, deve-se ter certa cautela na análise de dados, como será discutido caso a caso.

São três os objetivos principais na confecção desses indicadores. O primeiro deles é replicar para o Brasil parte do que foi feito por Florida para outras regiões (FLORIDA, 2002a, 2002b, 2005; FLORIDA; TINAGLI, 2004). Com esse intuito, são adaptados para o caso brasileiro alguns dos indicadores utilizados por esses autores, que são denominados aqui como proporção de trabalhadores no setor criativo e índice de qualificação superior. O segundo objetivo é estender essa análise sobre distribuição de indivíduos qualificados com a criação de novos indicadores, também citados anteriormente, e obtidos a partir dos microdados do Censo Demográfico de 2000. Por fim, pretende-se testar, para o Brasil, a hipótese feita por Florida (2002b), na qual regiões com uma atmosfera mais vibrante em termos de entretenimento seriam muito atraentes com relação à qualidade de vida, o que teria impacto marcante na atração de indivíduos qualificados e criativos. Com esse intuito, o índice de entretenimento apresentado por Florida (2002a, 2002b, 2005) é adaptado para o caso brasileiro.

Porém, antes da discussão dos resultados dos diversos indicadores, segue uma breve descrição de cada um deles, na mesma ordem em que aparecem no restante do texto.

\section{Definição dos indicadores}

Proporção de trabalhadores no setor criativo - Esse indicador é baseado e semelhante ao utilizado por Florida (2005), sendo uma adaptação para os dados brasileiros a partir da Classificação Brasileira de Ocupações, como descrito no Censo Demográfico de 2000 (IBGE, 2000). Esse índice corresponde à proporção de trabaIhadores em ocupações classificadas como criativas: membros superiores do poder público; dirigentes de organizações de interesse público e de empresas e gerentes; e profissionais das ciências e das artes. São excluídas as seguintes ocupações: técnicos de nível médio; trabalhadores de serviços administrativos; trabalhadores dos serviços; vendedores em lojas e mercados; trabaIhadores agropecuários, florestais, de caça e de pesca; trabalhadores da produção de bens e serviços industriais; trabalhadores de reparação e manutenção; e membros das forças armadas, policiais e bombeiros militares. O termo setor criativo apresenta limitações e imperfeições. Entretanto, para que uma comparabilidade fosse possível com os estudos de Florida (2002a, 2002b, 2005), utiliza-se a mesma definição e nomenclatura deste autor.

Índice de qualificação superior - Proporção de pessoas com nível superior ou mais de escolaridade. Esses indivíduos correspondem aos não-estudantes com nível superior e/ou com mestrado/doutorado e aos estudantes em algum desses dois níveis. Esse indicador é semelhante ao utilizado por Florida (2005) e é confeccionado para replicar parte das análises desse autor.

Índice de qualificação de pós-graduação Proporção de não-estudantes com mestrado/doutorado ou de estudantes cursando 
um desses níveis. Esse indicador é uma proxi para a capacidade de inovação em uma localidade diretamente relacionada a indivíduos altamente qualificados.

Índice de qualificação técnica superior - Proporção de trabalhadores com nível superior em ocupações classificadas como: profissionais policientíficos; das ciências exatas, físicas e da engenharia; ou das ciências biológicas, da saúde e afins. Ressalte-se que esse indicador e o próximo não incluem as pessoas que tinham como atividade principal o magistério superior. Esse indicador procura captar a capacidade de inovação técnica na sociedade não diretamente inserida nas instituições de ensino de nível superior do país.

Índice de qualificação técnica de pós-graduação - Proporção de trabalhadores com mestrado ou doutorado em ocupações classificadas como: profissionais policientíficos; das ciências exatas, físicas e da engenharia; ou das ciências biológicas, da saúde e afins. Esse indicador procura ser uma proxi para a presença de trabalhadores altamente qualificados em atividades técnicas da indústria e serviços não ligadas diretamente ao magistério superior.

Índice síntese - Os indicadores anteriormente descritos apresentam correlações positivas e significativas entre si, como será discutido a seguir, e são combinados em um único indicador. Como os valores de cada um desses cinco indicadores variam muito, para que todos tivessem o mesmo peso na confecção do indicador síntese, eles foram normalizados. O valor de cada variável foi dividido pelo valor máximo encontrado para a mesma variável. Assim, cada um dos indicadores passou a variar entre zero e um. Depois de obtidos esses indicadores normalizados, foi feita uma média simples destes.

Índice de alta tecnologia bruto - Massa salarial no município dos trabalhadores em ocupações técnicas com mestrado ou doutorado - os mesmos do índice de qualificação técnica de pós-graduação -, como proporção do total no Brasil. Pressupõe-se que os indivíduos altamente qualificados ocupados em áreas técnicas encontramse em indústrias ou serviços que utilizam tecnologia mais avançada. A massa salarial desses indivíduos seria uma proxi da dimensão desse tipo de atividade no município.

Índice de alta tecnologia relativo - $\mathrm{O}$ indicador bruto anterior depende, entre outros aspectos, da população do município. Já esse indicador é dividido pelo número de trabalhadores em todas as atividades no município, obtendo-se, assim, um indicador semelhante ao anterior, mas relativo. $\mathrm{Ou}$ seja, enquanto o primeiro estima principalmente pontos quantitativos, o segundo refere-se especialmente a características qualitativas.

Índice de entretenimento - Esse indicador é baseado no apresentado em Florida (2005), sendo uma adaptação do índice de boemia do autor para o caso brasileiro. Esse índice é a proporção de trabalhadores que eram ocupados em ocupações classificadas como profissionais de espetáculos e das artes: produtores de espetáculos; coreógrafos e bailarinos; atores, diretores de espetáculos e afins; compositores, músicos e cantores; desenhistas industriais (designer); escultores, pintores e afins; e decoradores de interiores e cenógrafos. $O$ índice é normalizado, ou seja, indica quantas vezes a proporção de determinado local é maior do que o valor médio para todas as áreas analisadas. Como descrito anteriormente, esse indicador foi confeccionado também com o objetivo de se testar a hipótese feita por Florida (2002b), de que locais com uma atmosfera vibrante seriam mais atrativos para indivíduos talentosos e criativos.

\section{Descrição dos resultados}

Como são muitos os municípios no Brasil (5.507 em 2000), este estudo detalha somente os dados mais relevantes entre todos os municípios. Quando foi julgado necessário, dependendo do indicador discutido, apenas as informações dos municípios com população acima de determinado patamar populacional são apresentados. Alguns dos resultados obtidos para o total dos municípios são mostrados em mapas, 
o que possibilita avaliar a heterogeneidade espacial brasileira para diversos indicadores de forma visual.

A Tabela 1 mostra os 25 municípios com as maiores proporções de trabalhadores na economia criativa e sua população em 2000. Esses valores variavam de $18,5 \%$ a $29,2 \%$, sendo que Niterói (RJ) ocupa o primeiro lugar entre todos os municípios brasileiros, com valores próximos ao observado para os EUA (FLORIDA; TINAGLI, 2004). Entre os municípios com os maiores valores, aparecem todas as capitais de Estado das regiões Sul e Sudeste: Porto Alegre (RS), Vitória (ES), Florianópolis (SC), Curitiba (PR), Belo Horizonte (MG), Rio de Janeiro (RJ) e São Paulo (SP). Outros municípios, inclusive os dois com valores mais elevados entre todos no Brasil, localizam-se na periferia de regióes metropolitanas: Niterói (RJ), Santana de Parnaíba (SP) e São Caetano do Sul (SP). Entre os 25 municípios apresentados na tabela, três são centros médios/grandes não pertencentes a regiões metropolitanas: Balneário do Camboriú (SC), Campinas (SP) e Santos (SP), sendo os dois últimos muito próximos da Região Metropolitana de São Paulo (RMSP). Os demais municípios, 12 no total, apresentam população abaixo de 50 mil habitantes.

O Mapa 1 mostra todos os municípios brasileiros classificados segundo a proporção de trabalhadores na economia criativa. Entre os 5.507 municípios no Brasil em 2000, 61 registravam cifras acima de $15 \%$, outros 422 apresentavam valores entre $10 \%$ e $15 \%$ e a maioria, mais de cinco mil, situava-se na faixa de $0 \%$ a $10 \%$. Este mapa foi confeccionado com o uso de gradientes e interpolação dos dados municipais e mostra os valores dessa variável "suavizados". Os valores apresentados na legenda foram escolhidos de forma a facilitar as comparações entre as diversas regiões do país.

TABELA 1

Proporção de trabalhadores na economia criativa para os municípios mais bem posicionados Brasil - 2000

\begin{tabular}{|c|c|c|c|}
\hline Colocação & Municípios & Proporção (\%) & População \\
\hline 1 & Niterói (RJ) & 29,2 & 459.451 \\
\hline 2 & São Caetano do Sul (SP) & 28,2 & 140.159 \\
\hline 3 & Baependi (MG) & 27,7 & 17.523 \\
\hline 4 & Águas de São Pedro (SP) & 26,3 & 1.883 \\
\hline 5 & Cipó (BA) & 24,7 & 14.285 \\
\hline 6 & Porto Alegre (RS) & 24,3 & 1.360 .590 \\
\hline 7 & Vitória (ES) & 23,8 & 292.304 \\
\hline 8 & Florianópolis (SC) & 23,7 & 342.315 \\
\hline 9 & Santos (SP) & 22,4 & 417.983 \\
\hline 10 & Cachoeirinha (PE) & 22,2 & 17.042 \\
\hline 11 & Jaguaribe (CE) & 22,2 & 35.062 \\
\hline 12 & Cesário Lange (SP) & 22,1 & 12.883 \\
\hline 13 & Nova Iguaçu de Goiás (GO) & 21,4 & 2.746 \\
\hline 14 & Curitiba (PR) & 20,9 & 1.587 .315 \\
\hline 15 & Silveiras (SP) & 20,7 & 5.378 \\
\hline 16 & Balneário Camboriú (SC) & 20,3 & 73.455 \\
\hline 17 & Belo Horizonte (MG) & 20,0 & 2.238 .526 \\
\hline 18 & Santana de Parnaíba (SP) & 19,9 & 74.828 \\
\hline 19 & Rio de Janeiro (RJ) & 19,9 & 5.857 .904 \\
\hline 20 & Garuva (SC) & 19,8 & 11.378 \\
\hline 21 & Campinas (SP) & 19,4 & 969.396 \\
\hline 22 & Lavandeira (TO) & 19,4 & 1.209 \\
\hline 23 & Itaiçaba (CE) & 19,4 & 6.579 \\
\hline 24 & Paulino Neves (MA) & 19,2 & 11.526 \\
\hline 25 & São Paulo (SP) & 18,5 & 10.435 .546 \\
\hline
\end{tabular}

Fonte: IBGE. Censo Demográfico, 2000. Dados trabalhados. 
MAPA 1

Proporção de trabalhadores na economia criativa por município - valores "suavizados" 2000

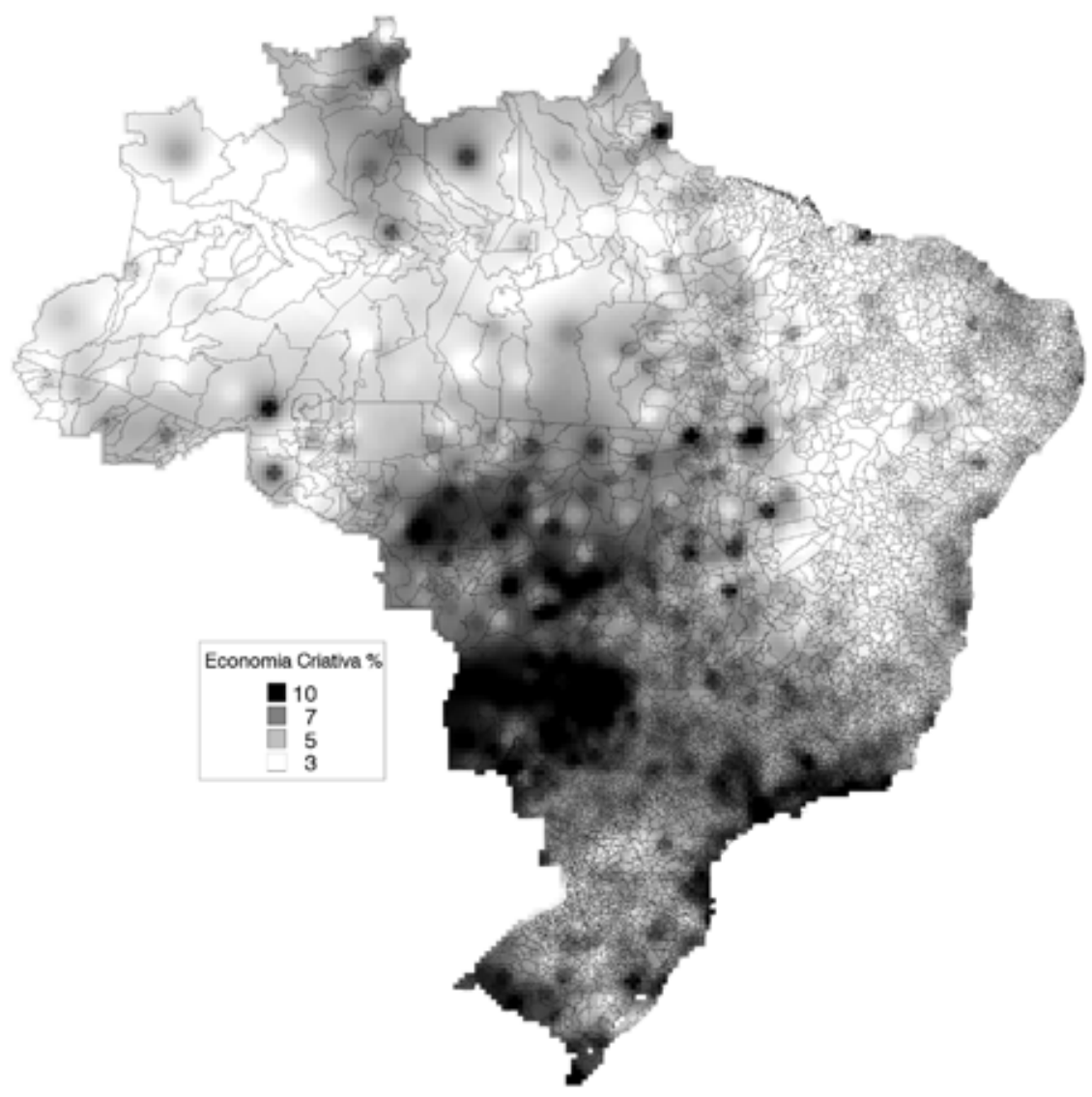

Fonte: IBGE. Censo Demográfico, 2000. Dados trabalhados.

Verifica-se que as regiões com os maiores valores são: parte da costa das regiões Sul/ Sudeste, desde Florianópolis (SC) até Cabo Frio (RJ); parte do interior de São Paulo; o Mato Grosso do Sul e parte do Mato Grosso; o extremo sul do Brasil; e o eixo Porto Alegre/Costa do Rio Grande do Sul. Como destaque negativo, com os menores valores para a proporção de trabalhadores na economia criativa, aparecem: grande parte do Nordeste; parte do norte de Minas Gerais; e a parte central da Região Norte. Essas são as principais áreas em termos de extensão territorial para tendências gerais. Além disso, nota-se uma marcante heterogeneidade espacial no Brasil para esse indicador.

Os 15 maiores valores para o índice de qualificação superior, assim como a população de cada um dos municípios, são mostrados na Tabela 2. Quase todos os municípios - os quatorze primeiros também apareceram na tabela anterior. A correlação entre a proporção de pessoas na economia criativa e o índice de qualificação superior é elevada $(0,73)$ e significativa em $1 \%$. Entretanto, ao contrário do observado na tabela anterior, nota-se que, entre os 15 valores mais elevados para o índice de qualificação superior no Brasil, aparece somente um município com população inferior a 70 mil habitantes: Águas de São Pedro (SP). Todos os demais são municípios médios ou grandes. Niterói (RJ) e São Caetano do Sul (SP) aparecem, mais uma vez, nas duas primeiras posições. Todas as capitais do Sul e do Sudeste também estão nessa 
TABELA 2

Índice de qualificação superior e de pós-graduação para os municípios mais bem posicionados Brasil - 2000

\begin{tabular}{|c|c|c|c|c|c|}
\hline \multicolumn{3}{|c|}{ Índice de qualificação superior } & \multicolumn{3}{|c|}{ Índice de qualificação de pós-graduação } \\
\hline Municípios & Índice & População & Municípios & Índice & População \\
\hline Niterói (RJ) & 14,0 & 459.451 & Viçosa (MG) & 5,83 & 64.854 \\
\hline São Caetano do Sul (SP) & 12,3 & 140.159 & Florianópolis (SC) & 4,66 & 342.315 \\
\hline Águas de São Pedro (SP) & 12,2 & 1.883 & São Carlos (SP) & 4,10 & 192.998 \\
\hline Santos (SP) & 12,0 & 417.983 & Niterói (RJ) & 3,20 & 459.451 \\
\hline Vitória (ES) & 10,6 & 292.304 & Lavras (MG) & 2,77 & 78.772 \\
\hline Porto Alegre (RS) & 10,3 & 1.360 .590 & Campinas (SP) & 2,68 & 969.396 \\
\hline Florianópolis (SC) & 10,2 & 342.315 & Porto Alegre (RS) & 2,54 & 1.360 .590 \\
\hline Curitiba (PR) & 8,68 & 1.587 .315 & Ilha Solteira (SP) & 2,47 & 23.996 \\
\hline Rio de Janeiro (RJ) & 8,50 & 5.857 .904 & São Caetano do Sul (SP) & 2,43 & 140.159 \\
\hline Belo Horizonte (MG) & 7,96 & 2.238 .526 & Botucatu (SP) & 2,14 & 108.306 \\
\hline Campinas (SP) & 7,85 & 969.396 & Santa Maria (RS) & 2,11 & 243.611 \\
\hline Balneário Camboriú (SC) & 7,81 & 73.455 & Rio de Janeiro (RJ) & 1,99 & 5.857 .904 \\
\hline Santana de Parnaíba (SP) & 7,67 & 74.828 & Araraquara (SP) & 1,96 & 182.471 \\
\hline São Paulo (SP) & 7,52 & 10.435 .546 & Piracicaba (SP) & 1,89 & 329.158 \\
\hline Ribeirão Preto (SP) & 7,39 & 504.923 & Vitória (ES) & 1,77 & 292.304 \\
\hline
\end{tabular}

Fonte: IBGE. Censo Demográfico, 2000. Dados trabalhados.

lista, em colocações similares ou superiores às observadas anteriormente. Além disso, muitos municípios do Estado de São Paulo encontram-se nesta lista, indicando o elevado nível de escolaridade no Estado.

O Mapa 2 mostra a distribuição do índice de qualificação superior para todos os municípios brasileiros. Grosso modo, o Brasil pode ser dividido em duas regiões com valores de índices muito distintos para esse indicador e de forma mais clara do que para a proporção de pessoas na economia criativa. Pode-se traçar uma linha divisória aproximada, começando na fronteira do Espírito Santo com a Bahia, passando pelo norte de Minas Gerias, norte de Goiás, Palmas (TO), divisas entre o Mato Grosso e Pará, e o centro de Rondônia. Ou seja, é possível fazer uma separação entre o Sul/Sudeste/Centro-Oeste - a parte com maiores índices - e o restante do país. Verifica-se que quase todo o Estado de São Paulo apresentava altos valores, como já destacado na análise da tabela anterior. Ressaltam-se, ainda, os valores elevados do norte do Paraná, sul do Rio de Janeiro, Mato Grosso do Sul e Rio Grande do Sul.

O terceiro indicador a ser discutido é o índice de qualificação de pós-graduação com os indivíduos com mestrado/doutorado e os estudantes nestes níveis - também mostrado na Tabela 2. Observa-se que os valores são muito inferiores aos observados para o indicador anterior. Além disso, este índice é muito influenciado pela presença de universidades públicas/privadas e instituições de pesquisa, que têm muitos mestres e doutores em seu corpo docente e muitos estudantes de mestrado/doutorado em seu corpo discente, principalmente quanto se analisam centros urbanos de tamanho médio, ou seja, população razoavelmente pequena para as dimensões da população universitária/científica. Esse parece ser o caso de Viçosa (MG), Lavras (MG), Rio Claro (SP), São Carlos (SP) e Botucatu (SP), entre outros. Algumas capitais de Estado das regiões Sul e Sudeste também aparecem na relação, porém, o município de São Paulo não está presente. Também nesta lista encontram-se alguns municípios das regiões metropolitanas e de tamanho médio/grande dessas mesmas duas regiões. Esse indicador apresenta uma correlação significativa e positiva com os anteriores, mas com magnitude menor: $0,51 \mathrm{com}$ a proporção de pessoas na economia criativa; e 0,58 com o índice de qualificação superior.

O índice de qualificação técnica superior é apresentado na Tabela 3. Também 


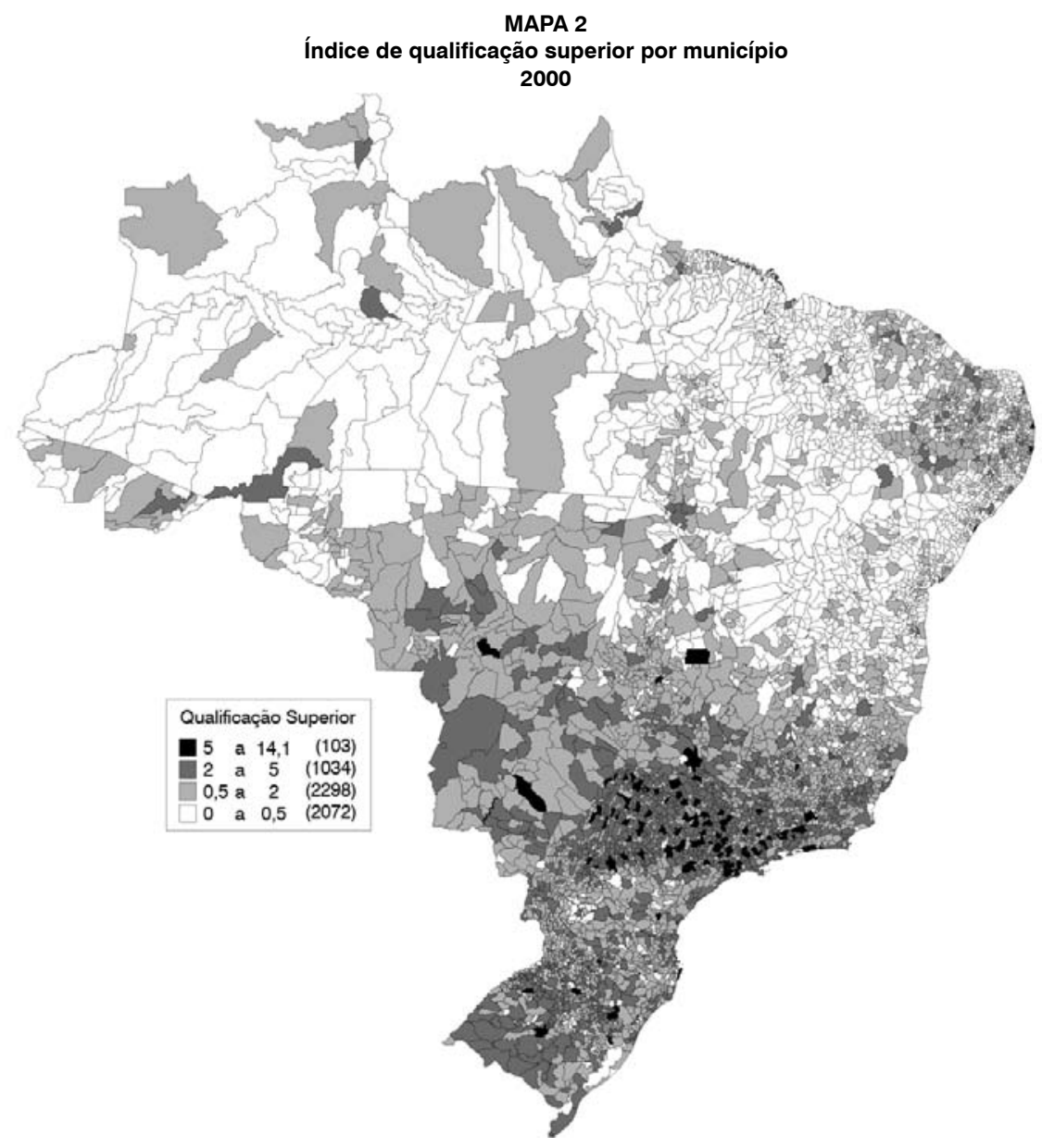

Fonte: IBGE. Censo Demográfico, 2000. Dados trabalhados.

nesta análise aparecem, entre os municípios com valores mais elevados, muitas capitais de Estado e centros médios/grandes das regiões Sul e Sudeste. Municípios na periferia de grandes regiões metropolitanas, como de São Paulo e do Rio de Janeiro - respectivamente, São Caetano do Sul e Niterói - também aparecem com certo destaque. Além desses, nota-se a presença de uma capital do Nordeste, Recife (PE), e de um município de pequena população, Oliveira de Fátima (AM).

Quando todos os municípios brasileiros são analisados em conjunto (dados não mostrados), verifica-se que a maioria dos que tinham valores acima de $2 \%, 121$ entre os 5.507, localiza-se em três Estados - São
Paulo, Rio de Janeiro e Minas Gerais - e na região Sul. Outros 613 municípios, com valores entre $1 \%$ e $2 \%$, também se localizam principalmente nestas áreas. A maioria dos municípios, $4.773(86,7 \%)$, apresentava valores inferiores a $1 \%$, indicando a concentração de pessoas especializadas em algumas regiões e municípios.

Este indicador apresenta correlações significativas e positivas com os demais indicadores já discutidos, principalmente com os dois primeiros - proporção de pessoas na economia criativa $(0,68)$; índice de qualificação superior $(0,71)$; índice de qualificação de pós-graduação $(0,54)$.

Os resultados para o índice de qualificação técnica de pós-graduação também 
TABELA 3

Índice de qualificação técnica superior e de pós-graduação para os municípios mais bem posicionados Brasil - 2000

\begin{tabular}{|c|c|c|c|c|c|}
\hline \multicolumn{3}{|c|}{ Índice de qualificação técnica superior } & \multicolumn{3}{|c|}{$\begin{array}{l}\text { Índice de qualificação técnica de pós-graduação para } \\
\text { municípios com mais de } 50 \text { mil habitantes }\end{array}$} \\
\hline Municípios & Índice & População & Municípios & Índice & População \\
\hline Niterói (RJ) & 8,06 & 459.451 & Niterói (RJ) & 0,877 & 459.451 \\
\hline Florianópolis (SC) & 5,52 & 342.315 & Viçosa (MG) & 0,673 & 64.854 \\
\hline Porto Alegre (RS) & 5,42 & 1.360 .590 & Botucatu (SP) & 0,629 & 108.306 \\
\hline São Caetano do Sul (SP) & 5,37 & 140.159 & Lavras (MG) & 0,625 & 78.772 \\
\hline Vitória (ES) & 5,22 & 292.304 & Florianópolis (SC) & 0,588 & 342.315 \\
\hline Santos (SP) & 5,05 & 417.983 & São Carlos (SP) & 0,550 & 192.998 \\
\hline Campinas (SP) & 4,69 & 969.396 & Rio de Janeiro (RJ) & 0,506 & 5.857 .904 \\
\hline Oliveira de Fátima (AM) & 4,40 & 958 & Campinas (SP) & 0,472 & 969.396 \\
\hline Rio de Janeiro (RJ) & 4,30 & 5.857 .904 & Vitória (ES) & 0,448 & 292.304 \\
\hline Belo Horizonte (MG) & 4,26 & 2.238 .526 & Seropédica (RJ) & 0,418 & 65.260 \\
\hline Ribeirão Preto (SP) & 4,21 & 504.923 & Porto Alegre (RS) & 0,351 & 1.360 .590 \\
\hline Curitiba (PR) & 4,00 & 1.587 .315 & Mairiporã (SP) & 0,345 & 60.111 \\
\hline Recife (PE) & 3,80 & 1.422 .905 & Balneário Camboriú (SC) & 0,343 & 73.455 \\
\hline São Paulo (SP) & 3,63 & 10.435 .546 & Ribeirão Preto (SP) & 0,335 & 504.923 \\
\hline Jundiaí (SP) & 3,51 & 323.397 & Santos (SP) & 0,328 & 417.983 \\
\hline
\end{tabular}

Fonte: IBGE. Censo Demográfico, 2000. Dados trabalhados.

são mostrados na Tabela 3. Essa variável apresenta correlações significativas e positivas, mas com uma magnitude muito inferior àquela observada para as demais correlações (respectivamente: 0,27; 0,21; 0,38; e 0,41 ). Entre os 15 municípios brasileiros com os maiores valores, a maioria tinha população muito pequena. Ou seja, como os valores para esse indicador são muito baixos, pois a proporção de trabalhadores em ocupações classificadas como profissionais policientíficos, das ciências exatas, físicas e da engenharia, ou das ciências biológicas, da saúde e afins com qualificação mínima de mestre é muito pequena, esses resultados positivos são obtidos também devido a uma amostra muito pequena em municípios de pequena população. Para a análise não ficar enviesada por esse tipo de problema e ser mais ilustrativa, são apresentados apenas os resultados para municípios com mais de 50 mil habitantes. Nota-se que muitos dos municípios que aparecem na Tabela 3 também estavam presentes nas anteriores, como algumas das capitais, municípios localizados na periferia de regiões metropolitanas e centros médios/ grandes das regióes Sul e Sudeste.

Os indicadores anteriormente descritos apresentam correlações positivas e signifi- cativas entre si, como discutido para cada um deles em separado. Assim, na confecção do indicador síntese, todos eles são combinados em um único indicador. Como já discutido, este indicador é a média simples de todos os cincos anteriores normalizados. Por definição, os valores podem variar de 0 a 1. Os resultados para todos os municípios brasileiros são mostrados na Tabela 4. Entre as capitais, Florianópolis (SC) obteve o indicador mais elevado, seguida por Porto Alegre (RS), Vitória (ES), Rio de Janeiro (RJ), Curitiba (PR), Belo Horizonte (MG), São Paulo (SP), Recife (PE) e Brasília (DF). Entretanto, no total dos municípios brasileiros, Niterói (RJ) registrou o índice mais elevado, como já foi observado para outros indicadores, com um valor muito superior a todos os demais. Outros municípios localizados na periferia de regiões metropolitanas também apresentaram cifras elevadas, como São Caetano do Sul (SP) e Santana de Parnaíba (SP). Muitos centros urbanos médios/ grandes das regiões Sul e Sudeste também obtiveram valores elevados, como Santos (SP), Campinas (SP), Viçosa (MG), São Carlos (SP), Ribeirão Preto (SP), Botucatu (SP), Balneário Camboriú (SC), Santa Maria (RS), Lavras (MG) e Araraquara (SP). Apenas três 
TABELA 4

Índice síntese para os municípios mais bem posicionados

Brasil - 2000

\begin{tabular}{llrr}
\hline Colocação & Municípios & Índice síntese & População \\
\hline 1 & Niterói (RJ) & 0,792 & 459.451 \\
2 & Florianópolis (SC) & 0,659 & 342.315 \\
3 & São Caetano do Sul (SP) & 0,613 & 140.159 \\
4 & Porto Alegre (RS) & 0,568 & 1.360 .590 \\
5 & Vitória (ES) & 0,545 & 292.304 \\
6 & Santos (SP) & 0,529 & 417.983 \\
7 & Águas de São Pedro (SP) & 0,504 & 1.883 \\
8 & Campinas (SP) & 0,497 & 969.396 \\
9 & Rio de Janeiro (RJ) & 0,480 & 5.857 .904 \\
10 & Viçosa (MG) & 0,476 & 64.854 \\
11 & Curitiba (PR) & 0,447 & 1.587 .315 \\
12 & São Carlos (SP) & 0,437 & 192.998 \\
13 & Belo Horizonte (MG) & 0,432 & 2.238 .526 \\
14 & Ribeirão Preto (SP) & 0,411 & 504.923 \\
15 & São Paulo (SP) & 0,390 & 10.435 .546 \\
16 & Botucatu (SP) & 0,386 & 108.306 \\
17 & Balneário Camboriú (SC) & 0,385 & 73.455 \\
18 & Santana de Parnaíba (SP) & 0,384 & 74.828 \\
19 & Recife (PE) & 0,372 & 1.422 .905 \\
20 & Jardim Olinda (PR) & 0,363 & 1.523 \\
21 & Santa Maria (RS) & 0,363 & 243.611 \\
22 & Brasília (DF) & 0,363 & 2.051 .146 \\
23 & Lavras (MG) & 0,362 & 78.772 \\
24 & Araraquara (SP) & 0,358 & 182.471 \\
25 & Ilha Solteira (SP) & 0,350 & 23.996 \\
\hline
\end{tabular}

Fonte: IBGE. Censo Demográfico, 2000. Dados trabalhados. municípios, entre os apresentados na tabela, fogem dessa regra geral: dois no Estado de São Paulo - Ilha Solteira e Águas de São Pedro - e Jardim Olinda, no Paraná.

O Mapa 3 mostra o índice síntese "suavizado" para todos os municípios brasileiros. Nota-se que a área onde se concentram os valores elevados compreende a costa entre Florianópolis e Cabo Frio, grande parte do interior de São Paulo, parte do norte do Paraná, parte do sul/sudoeste de Minas Gerais e parte do Mato Grosso do Sul. Por outro lado, grande parte do Nordeste e Norte apresenta indicadores com baixo valor.

O próximo indicador a ser discutido é o índice de alta tecnologia bruto. Pressupõese que a massa salarial dos indivíduos qualificados ocupados na área técnica seja uma proxi da dimensão das indústrias ou serviços que utilizam uma tecnologia mais avançada. $O$ valor de cada localidade foi dividido pelo total no país, para se obter uma idéia mais precisa da real dimensão relativa das atividades de alta tecnologia no local. Os valores referem-se ao local de residência do indivíduo e não ao local

de trabalho. Uma pessoa pode morar em um município e trabalhar em outro, o que ocorre principalmente em regiões metropolitanas.

Como esperado, todos os municípios presentes na Tabela 5 são populosos, uma vez que o indicador é bruto. O município com menor população é Florianópolis (SC), com quase 350 mil habitantes em 2000, ou $0,2 \%$ do Brasil. Os 15 municípios apresentados na tabela detinham $62,1 \%$ de toda a massa salarial de alta tecnologia do Brasil e somente $19,6 \%$ da população nacional. São Paulo e Rio de Janeiro, os dois municípios mais populosos do país, com 9,5\% do total da população, tinham mais de um terço da massa salarial brasileira $(33,5 \%)$. Os oito municípios com os maiores valores de índice de alta tecnologia bruto, que são esses dois citados e mais Belo Horizonte, Porto Alegre, Brasília, Campinas, Curitiba e Salvador, detinham mais de $50 \%$ do total. Ou seja, os valores são altamente concentrados em poucos municípios. Verifica-se que 11 das capitais brasileiras aparecem na lista, incluindo quase todas do Sul e Sudeste, 




Fonte: IBGE. Censo Demográfico, 2000. Dados trabalhados.

uma da Região Norte, as três mais populosas do Nordeste e a mais populosa do Centro-Oeste. Todos os demais municípios são de tamanho médio/grande dos Estados de São Paulo ou do Rio de Janeiro.

Entre os 5.507 municípios brasileiros em $2000,4.580(83,2 \%)$ possuíam valores nulos para esse indicador, ou seja, não tinham qualquer indivíduo com titulação mínima de mestre trabalhando em atividades técni- cas. Outros $856(15,5 \%)$ apresentavam um valor até aproximadamente um milésimo do observado em São Paulo. Isto é, o tamanho da indústria/serviços de alta tecnologia, segundo a proxi utilizada aqui, era marcadamente menor do que para o município de São Paulo. Somente 68 municípios detinham valores acima de um milésimo do município de São Paulo, muitos na periferia de regiões metropolitanas. $^{3}$

\footnotetext{
${ }^{3}$ Segue a lista completa de todos eles: Região Norte (Manaus e Belém); Região Nordeste (São Luís, Teresina, Fortaleza, Natal, Campina Grande, João Pessoa, Recife, Maceió, Aracaju e Salvador); Minas Gerais (Belo Horizonte, Juiz de Fora, Lavras, Uberlândia e Viçosa); Espírito Santo (Vila Velha - RM de Vitória e Vitória); Rio de Janeiro (Macaé, Niterói - RMRJ, Nova Iguaçu - RMRJ, Petrópolis, Rio de Janeiro e Volta Redonda); São Paulo (Americana - RM de Campinas, Araraquara, Bauru, Botucatu, Campinas, Guarujá - RM da Baixada Santista, Guarulhos - RMSP, Itu, Jundiaí, Marília, Moji das Cruzes RMSP, Osasco - RMSP, Piracicaba, Ribeirão Preto, Rio Claro, Santana de Parnaíba - RMSP, Santo André - RMSP, Santos - RM da Baixada Santista, São Bernardo do Campo - RMSP, São Caetano do Sul - RMSP, São Carlos, São José do Rio Preto, São José dos Campos, São Paulo, Sorocaba e Taubaté); Paraná (Curitiba, Londrina, Maringá e São José dos Pinhais - RM de Curitiba); Santa Catarina (Chapecó, Florianópolis e Joinville); Rio Grande do Sul (Caxias do Sul, Passo Fundo, Pelotas Porto Alegre e Santa Maria); Região Centro-Oeste (Campo Grande, Cuiabá, Anápolis, Goiânia e Brasília).
} 
TABELA 5

Índice de alta tecnologia bruto e relativo para os municípios mais bem posicionados Brasil - 2000

\begin{tabular}{|c|c|c|c|c|c|}
\hline \multicolumn{3}{|c|}{ Índice de alta tecnologia bruto } & \multicolumn{3}{|c|}{$\begin{array}{l}\text { Índice de alta tecnologia relativo para municípios } \\
\text { com mais de } 50 \text { mil habitantes }\end{array}$} \\
\hline Municípios & Índice & População & Municípios & Índice & População \\
\hline São Paulo (SP) & 17,7 & 6,1 & Niterói (RJ) & 36,2 & 459.451 \\
\hline Rio de Janeiro (RJ) & 15,8 & 3,4 & Botucatu (SP) & 33,7 & 108.306 \\
\hline Belo Horizonte (MG) & 3,6 & 1,3 & Lavras (MG) & 29,4 & 78.772 \\
\hline Porto Alegre (RS) & 3,4 & 0,8 & Florianópolis (SC) & 24,5 & 342.315 \\
\hline Brasília (DF) & 3,3 & 1,2 & Santana de Parnaíba (SP) & 22,8 & 74.828 \\
\hline Campinas (SP) & 2,9 & 0,6 & Campinas (SP) & 22,1 & 969.396 \\
\hline Curitiba (PR) & 2,9 & 0,9 & Rio de Janeiro (RJ) & 21,8 & 5.857 .904 \\
\hline Salvador (BA) & 2,4 & 1,4 & Viçosa (MG) & 21,7 & 64.854 \\
\hline Niterói (RJ) & 2,2 & 0,3 & Santos (SP) & 21,6 & 417.983 \\
\hline Recife (PE) & 1,7 & 0,8 & São Carlos (SP) & 21,4 & 192.998 \\
\hline Fortaleza (CE) & 1,5 & 1,3 & Porto Alegre (RS) & 18,0 & 1.360 .590 \\
\hline Belém (PA) & 1,2 & 0,8 & Vitória (ES) & 17,7 & 292.304 \\
\hline Santos (SP) & 1,2 & 0,2 & São José dos Campos (SP) & 16,3 & 539.313 \\
\hline Florianópolis (SC) & 1,2 & 0,2 & Balneário Camboriú (SC) & 14,9 & 73.455 \\
\hline São José dos Campos (SP) & 1,1 & 0,3 & Seropédica (RJ) & 14,3 & 65.260 \\
\hline Total & 62,1 & 19,6 & - & - & - \\
\hline
\end{tabular}

Fonte: IBGE. Censo Demográfico, 2000. Dados trabalhados.

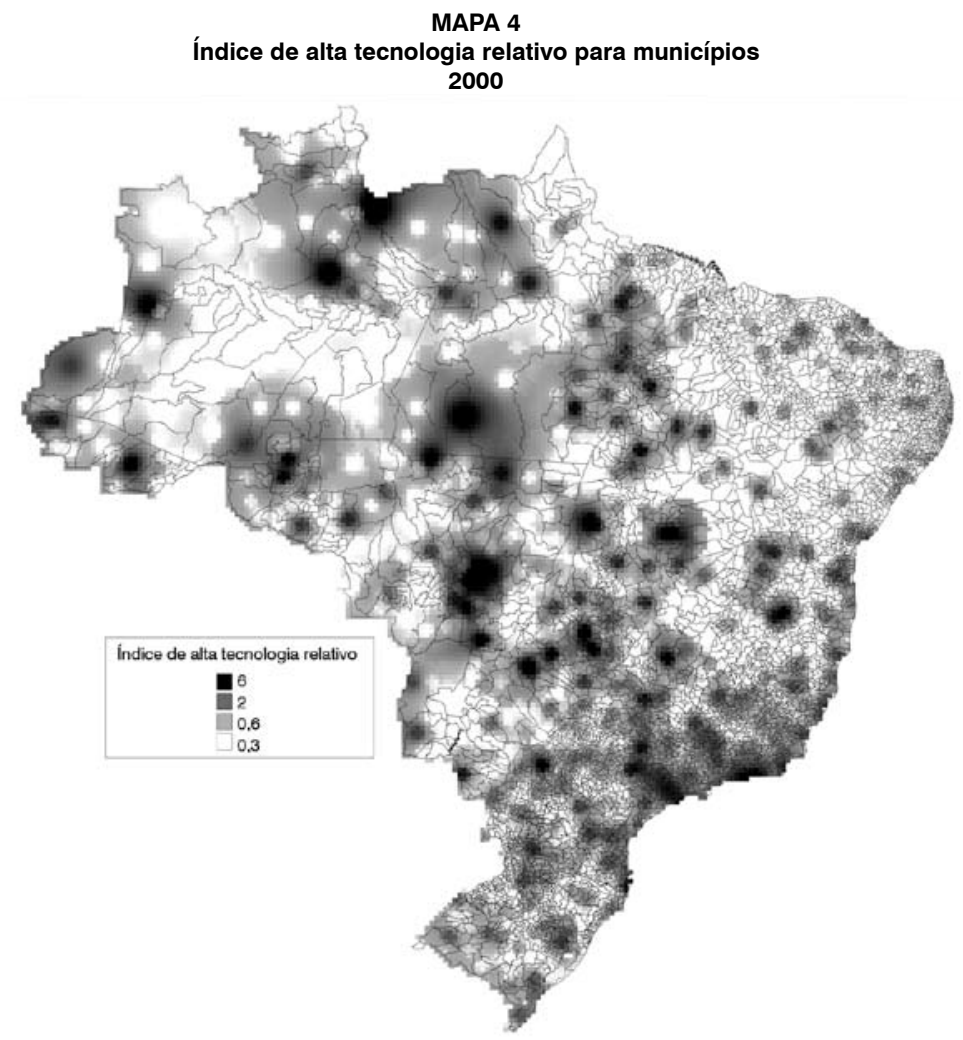

Fonte: IBGE. Censo Demográfico, 2000. Dados trabalhados. 
Esse indicador depende, entre outros aspectos, da população do município. O índice de alta tecnologia relativo é a razão entre esse indicador e o número de trabalhadores em todas as atividades no município. Como são vários os municípios muito pequenos com valores elevados para esse indicador, possivelmente por desvios estatísticos causados por pequenas amostras, optou-se por mostrar os resultados para municípios com mais de 50 mil habitantes (Tabela 5). Niterói (RJ) - o município com o maior valor para o índice síntese também detém o maior valor para o índice de alta tecnologia relativo. Muitos dos municípios mostrados nessa tabela também apareceram na anterior, como as capitais do Sul e Sudeste, com exceção de Belo Horizonte (MG), e centros urbanos e da periferia das regiões metropolitanas dessas regiões. Entretanto, verifica-se a presença de municípios de menor população, muitos também com um alto índice de qualificação de pós-graduação, como Botucatu (SP), Lavras (MG) e Viçosa (MG), indicando spillovers das atividades acadêmicas.

O Mapa 4, com os dados para este último indicador, mostra que as principais áreas com valores elevados estão na região Sudeste. Um dos principais pólos de alta tecnologia é o eixo Guarujá (SP)-Americana (SP), incluindo o município de São Paulo (SP). Outro, também no estado de São Paulo e muito próximo desse primeiro, é o eixo Botucatu (SP)-São Carlos (SP), que de certa maneira se funde com o primeiro. O Estado do Rio de Janeiro também conta com dois pólos de alta tecnologia que se fundem: um centrado nos municípios do Rio de Janeiro/Niterói; e outro em torno de Macaé. Outras áreas de destaque no Sudeste são: a localizada em torno de Belo

TABELA 6

Índice de entretenimento para municípios com mais de 50 mil habitantes Brasil - 2000

\begin{tabular}{|c|c|c|c|}
\hline Colocação & Municípios & Índice de entretenimento & População \\
\hline 1 & Tucano (BA) & 5,18 & 50.948 \\
\hline 2 & Ipirá (BA) & 4,94 & 61.746 \\
\hline 3 & Ouro Preto (MG) & 4,52 & 66.277 \\
\hline 4 & Leopoldina (MG) & 3,43 & 50.097 \\
\hline 5 & Porto Seguro (BA) & 2,96 & 95.721 \\
\hline 6 & Aracati (BA) & 2,27 & 61.187 \\
\hline 7 & Juazeiro do Norte (CE) & 2,05 & 212.133 \\
\hline 8 & Gravatá (PE) & 1,85 & 67.273 \\
\hline 9 & Embu (SP) & 1,83 & 207.663 \\
\hline 10 & Parintins (AM) & 1,83 & 92.118 \\
\hline 11 & Canindé (CE) & 1,70 & 69.601 \\
\hline 12 & Parnaíba (PI) & 1,68 & 132.282 \\
\hline 13 & Florianópolis (SC) & 1,64 & 342.315 \\
\hline 14 & São Cristóvão (SE) & 1,64 & 64.647 \\
\hline 15 & Formiga (MG) & 1,58 & 62.907 \\
\hline 16 & Niterói (RJ) & 1,54 & 459.451 \\
\hline 17 & Saquarema (RJ) & 1,52 & 52.461 \\
\hline 18 & Cotia (SP) & 1,52 & 148.987 \\
\hline 19 & Embu-Guaçu (SP) & 1,47 & 56.916 \\
\hline 20 & São João del Rei (MG) & 1,46 & 78.616 \\
\hline 21 & Floriano (PI) & 1,45 & 54.591 \\
\hline 22 & Cascavel (PR) & 1,41 & 57.129 \\
\hline 23 & Rio de Janeiro (RJ) & 1,37 & 5.857 .904 \\
\hline 24 & Itamaraju (BA) & 1,36 & 64.144 \\
\hline 25 & Mairiporã (SP) & 1,36 & 60.111 \\
\hline
\end{tabular}

Fonte: IBGE. Censo Demográfico, 2000. Dados trabalhados. 
Horizonte (MG), incluindo um eixo noroeste; a região em torno de Vitória (ES); e as áreas nos arredores de Uberaba (MG), de Lavras (MG) e de Salinas (MG).

$O$ índice de entretenimento, como definido por Florida (2002a, 2005), é replicado para o caso brasileiro. Como são vários os municípios com população muito pequena que detinham valores elevados, selecionaram-se apenas aqueles com mais de 50 mil habitantes, como mostrado na Tabela 6. Como discutido, os valores são normalizados. Três municípios tinham valores acima de quatro para esse indicador, todos de tamanho pequeno/médio, sendo que apenas um município muito populoso aparece na lista, Rio de Janeiro (RJ), na $23^{\text {a }}$ posição. Outros dois centros urbanos médios de destaque são Niterói (RJ) e Florianópolis (SC). O Nordeste e o Sudeste detêm quase todos os municípios citados, muitos na RMSP (Embu, Cotia, Embu-Guaçu e Mariporã), outros no interior dos Estados de Minas Gerais, Rio de Janeiro, Bahia, Ceará, Pernambuco, Piauí e Sergipe, muitos na costa.

O Mapa 5 mostra os resultados para todo o país, lembrando, mais uma vez, que para municípios com população muito pequena podem ocorrer variabilidades devido a pequenas amostras. Algumas áreas destacam-se com altos valores para o índice de entretenimento. Uma área razoavelmente extensa localiza-se no Nordeste, abrangendo toda a costa do Ceará e partes do interior desse Estado e da Paraíba. Outra

MAPA 5

Índice de entretenimento para municípios

2000

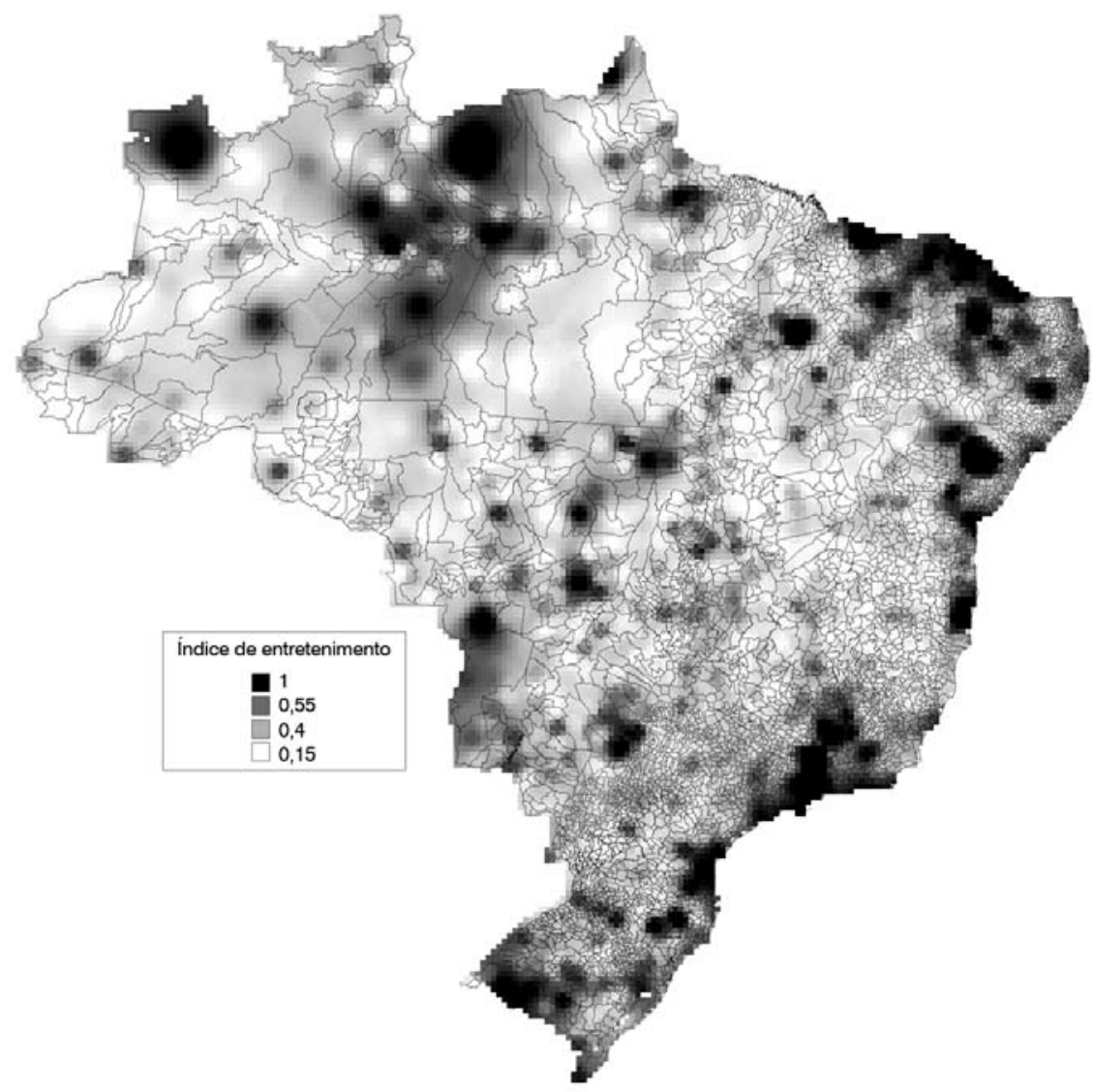

Fonte: IBGE. Censo Demográfico, 2000. Dados trabalhados. 
área grande compreende o sul da RMSP, costa centro/norte de São Paulo, costa centro/sul do Rio de Janeiro e parte do interior de São Paulo e de Minas Gerais.

\section{Análise com aglomerados}

Os resultados obtidos com análise multivariada utilizando a técnica de aglome- rados são mostrados a seguir. Essa técnica permite classificar observações conforme a similaridade entre elas (HAIR et al., 2006). Anteriormente, os municípios brasileiros foram descritos conforme uma série de indicadores. O objetivo da análise de aglomerados empreendida aqui é agregar esses municípios em grupos aproximadamente homogêneos conforme suas característi-

TABELA 7

Análise de aglomerados com a proporção de trabalhadores na economia criativa, índice síntese e índice de entretenimento

Brasil - 2000

\begin{tabular}{ll}
\hline Características do aglomerado & Composição \\
\hline 1 -Todos os indicadores com & Florianópolis (SC) e Niterói (RJ)
\end{tabular}

valores muito elevados

2-Todos os indicadores com valores elevados

3- Valores médios para todos os índices

4- Valores baixos para todos os índices

5- Valores muito baixos para todos os índices
Recife (PE), Belo Horizonte (MG), Vitória (ES), Rio de Janeiro (RJ), Campinas (SP), Santos (SP), São Caetano do Sul (SP), São Paulo (SP), Curitiba (PR), Balneário Camboriú (SC) e Porto Alegre (RS)

Belém (PA), Palmas (TO), São Luís (MA), Teresina (PI), Fortaleza (CE), Natal (RN), Campina Grande (PB), Olinda (PE), Maceió (AL), Aracaju (SE), Lauro de Freitas (BA), Salvador (BA), Divinópolis (MG), Poços de Caldas (MG), Pouso Alegre (MG), Uberaba (MG), Uberlândia (MG), Varginha (MG), Vila Velha (ES), Petrópolis (RJ), Resende (RJ), Teresópolis (RJ),

Volta Redonda (RJ), Atibaia (SP), Guaratinguetá (SP), Itapetininga (SP), Mairiporã (SP), Pindamonhangaba (SP), Taubaté (SP), Foz do Iguaçu (PR), Ponta Grossa (PR), Blumenau (SC), Criciúma (SC), Itajaí (SC), Joinville (SC), Lages (SC), São José (SC), Bagé (RS), Caxias do Sul (RS), Pelotas (RS), Santa Maria (RS), São Leopoldo (RS), Campo Grande (MS) e Goiânia (GO)

Ji-Paraná (RO), Porto Velho (RO), Rio Branco (AC), Macapá (AP), Crato (CE), Sobral (CE), Parnamirim (RN), Mossoró (RN), Garanhuns (PE), Barreiras (BA), Araguari (MG), Barbacena (MG), Conselheiro Lafaiete (MG), Contagem (MG), Governador Valadares (MG), Ipatinga (MG), Montes Claros (MG), Patos de Minas (MG), Sete Lagoas (MG), Teófilo Otoni (MG), Cachoeiro de Itapemirim (ES), Colatina (ES), Linhares (ES) Barra Mansa (RJ), Campos dos Goytacazes (RJ), Macaé (RJ), Nilópolis (RJ), Nova Friburgo (RJ), Araras (SP), Barretos (SP), Barueri (SP), Bragança Paulista (SP), Catanduva (SP), Franca (SP), Guarulhos (SP), Indaiatuba (SP), Itu (SP), Jacareí (SP), Jaú (SP), Limeira (SP), Mogi Guaçu (SP), Osasco (SP), Ourinhos (SP), Ribeirão Pires (SP), Apucarana (PR), Cascavel (PR), Guarapuava (PR), Telêmaco Borba (PR), Chapecó (SC), Jaraguá do Sul (SC), Cachoeirinha (RS), Canoas (RS), Novo Hamburgo (RS), Rio Grande (RS), Santa Cruz do Sul (RS), Uruguaiana (RS), Dourados (MS), Rondonópolis (MT), Anápolis (GO), Jataí (GO) e Rio Verde (GO)

Abaetetuba (PA), Castanhal (PA), Marabá (PA), Caxias (MA), Codó (MA), São José de Ribamar (MA), Caucaia (CE), Maracanaú (CE), Santa Rita (PB), Cabo de Santo Agostinho (PE), Camaragibe (PE), Vitória de Santo Antão (PE), Camaçari (BA), Juazeiro (BA), Vitória da Conquista (BA), Betim (MG), Ibirité (MG), Ribeirão das Neves (MG), Cariacica (ES), São Mateus (ES), Belford Roxo (RJ), Duque de Caxias (RJ), Magé (RJ), Nova Iguaçu (RJ), Queimados (RJ), São João de Meriti (RJ), Seropédica (RJ), Carapicuíba (SP), Cubatão (SP), Diadema (SP), Ferraz de Vasconcelos (SP), Francisco Morato (SP), Franco da Rocha (SP), Hortolândia (SP), Itapevi (SP), Itaquaquecetuba (SP), Mauá (SP), Santa Bárbara d'Oeste (SP), Sumaré (SP), Colombo (PR), São José dos Pinhais (PR), Alvorada (RS), Sapucaia do Sul (RS), Águas Lindas de Goiás (GO) e Luziânia (GO) 
(continuação)

\begin{tabular}{l} 
Características do aglomerado \\
\hline 6- Valores baixos para a proporção de \\
trabalhadores na economia criativa e \\
para o índice síntese e muito elevados \\
para o índice de entretenimento \\
7- Valores médios para a proporção \\
de trabalhadores na economia criativa \\
e para o índice síntese e baixos \\
para o índice de entretenimento
\end{tabular}

8- Valores baixos para a proporção de trabalhadores na economia criativa e para o índice síntese e médios para o índice de entretenimento

\section{Composição}

Parnaíba (PI), Juazeiro do Norte (CE), Cotia (SP) e Embu (SP)

João Pessoa (PB), Juiz de Fora (MG), Lavras (MG), Viçosa (MG), Americana (SP), Araçatuba (SP), Araraquara (SP), Bauru (SP), Botucatu (SP), Jundiaí (SP), Marília (SP), Moji das Cruzes (SP), Piracicaba (SP), Presidente Prudente (SP), Ribeirão Preto (SP), Rio Claro (SP), Santana de Parnaíba (SP), Santo André (SP), São Bernardo do Campo (SP), São Carlos (SP), São José do Rio Preto (SP), São José dos Campos (SP), Sorocaba (SP), Londrina (PR), Maringá (PR), Passo Fundo (RS), Cuiabá (MT) e Brasília (DF)

Manaus (AM), Boa Vista (RR), Ananindeua (PA), Santarém (PA), Araguaína (TO), Imperatriz (MA), Timon (MA), Caruaru (PE), Jaboatão dos Guararapes (PE), Paulista (PE), Petrolina (PE), Arapiraca (AL), Nossa Senhora do Socorro (SE), Alagoinhas (BA), Feira de Santana $(B A)$, Ilhéus (BA), Itabuna (BA), Jequié (BA), Teixeira de Freitas (BA), Sabará (MG), Santa Luzia (MG), Serra (ES), Angra dos Reis (RJ), Cabo Frio (RJ), Itaboraí (RJ), São Gonçalo (RJ), Guarujá (SP), Itapecerica da Serra (SP), Praia Grande (SP), São Vicente (SP), Suzano (SP), Taboão da Serra (SP), Paranaguá (PR), Pinhais (PR), Palhoça (SC), Gravataí (RS), Viamão (RS), Várzea Grande (MT) e Aparecida de Goiânia (GO)

Fonte: IBGE. Censo Demográfico, 2000. Dados trabalhados.

cas. Assim, sintetiza-se a heterogeneidade regional brasileira entre as diversas localidades em alguns grupos distintos.

Como são muitos os municípios, para que a análise de aglomerados seja mais ilustrativa, foram selecionados aqueles que tinham uma população superior a 100 mil habitantes em 2000 e aqueles com um valor até $1 / 2000$ do índice de alta tecnologia bruta de São Paulo (SP), também para este ano, em um total de 234. Ou seja, todos os municípios populosos ou que têm uma indústria/serviços de alta tecnologia de tamanho relativamente grande, como medido pela proxi utilizada aqui, foram analisados.

Um estudo com todos os indicadores de qualificação - alguns deles muito correlacionados - e somente um índice de entretenimento apresentaria um viés para a qualificação (GOLGHER, 2006b). Com o objetivo de diminuir esse viés, foi feita a análise com aglomerados com apenas três variáveis: proporção de trabalhadores na economia criativa; índice síntese; e índice de entretenimento.

Os resultados dessa análise, que conta com oito aglomerados, são mostrados na Tabela 7, que apresenta as características e a composição de cada um deles. O aglomerado de número 1 categoriza os municípios que tinham todos os indicadores com valores muito superiores aos demais municípios, sendo composto somente por Florianópolis (SC) e Niterói (RJ), ambos mais uma vez em destaque. $\mathrm{O}$ aglomerado 2 tinha valores também elevados para todos os indicadores, mas com cifras um pouco inferiores a esses dois municípios, e inclui capitais e centros urbanos do Sul e do Sudeste do país e Recife (PE). O terceiro aglomerado apresenta valores médios para todos os indicadores, sendo formado por várias capitais do Norte, Nordeste e CentroOeste e municípios do interior do Sul e do Sudeste. Com valores inferiores aparece o quarto aglomerado, que contém municípios do interior de todas as macrorregiões, mas principalmente do Sul e do Sudeste, além de duas capitais do Norte (Porto Velho RO e Rio Branco - AC). O aglomerado 5 apresenta valores muito baixos para todos os indicadores e contém somente municípios do interior, muitos do Nordeste e da periferia das regiões metropolitanas do Sudeste. Esses cinco aglomerados possuem indicadores com valores relativos similares para os três indicadores em um gradiente de cifras do mais elevado para o 
mais baixo: aglomerado $1>$ aglomerado $2>$ aglomerado $3>$ aglomerado $4>$ aglomerado 5 . Os demais têm características distintas. 0 aglomerado 6 , com apenas quatro municípios, dois no Nordeste e dois na periferia da RMSP, destaca-se pelos altos valores do índice de entretenimento e baixos valores para os demais indicadores. 0 aglomerado 7 apresenta valores baixos para o índice de entretenimento e médio para os demais. São categorizados com essas características muitos municípios do interior das regiões Sul e Sudeste, além de três capitais, João Pessoa (PB), Cuiabá (MT) e Brasília (DF). O aglomerado 8 difere do 4, principalmente, por apresentar valores mais elevados para o entretenimento. Nota-se a presença de muitos municípios do interior do Nordeste e Sudeste, além de duas capitais do Norte: Manaus (AM) e Boa Vista (RR).

A análise com aglomerados permite classificar os principais municípios segundo os valores de seus indicadores. São muitos os fatores que influenciam o valor desses indicadores, e a seguir analisam-se econometricamente alguns desses fatores que impactam na proporção de trabalhadores na economia criativa e no índice síntese.

\section{Análises econométricas}

São dois os objetivos principais dos estudos econométricos empreendidos aqui. $\mathrm{O}$ primeiro, como enunciado anteriormente, é analisar alguns dos fatores correlacionados com a distribuição de indivíduos qualificados nos municípios brasileiros. O segundo é testar a hipótese de Florida (2002b), segundo a qual indivíduos qualificados tendem a ser atraídos por locais com atmosfera mais vibrante. Para tanto, são apresentadas análises de regressão múltipla com mínimos quadrados ordinários (MQO), em dois grupos de modelos.

No primeiro grupo são inicialmente analisados como variáveis dependentes dois dos indicadores apresentados na análise descritiva: a proporção de trabalhadores na economia criativa; e o índice de qualificação superior. Em seguida, como será detalhado a seguir, duas outras variáveis dependentes também são analisadas: a proporção ajustada de trabalhadores na economia criativa; e o índice síntese ajustado.

Como discutido anteriormente na introdução desse trabalho, e também como mostrado de forma empírica na análise descritiva dos dados, são muitos os fatores que influenciam a distribuição dos indivíduos qualificados no Brasil. Para analisar alguns desses efeitos são incluídas 12 variáveis independentes no modelo. Segue uma explicação sobre cada uma delas.

De forma geral, municípios com população maior e capitais de estado tendem a apresentar valores mais elevados para os indicadores de qualificação do que os demais. São incluídas duas variáveis que tratam dessas características: uma numérica, o logaritmo da população do município; e uma dummy, se o município é capital ou não (1 para capital, 0 para interior). O logaritmo se justifica por causa da distribuição assimétrica dos valores de população.

A distribuição de indivíduos qualificados também é afetada pela localização do município. Para estudar esse efeito, são incluídas no modelo quatro dummies de localização: se o município situa-se nas Regiões Norte, Sudeste, Sul ou Centro-Oeste (1 se localiza, 0 se não se localiza. A variável do Nordeste foi a omitida).

A sofisticação do mercado de trabalho também afeta a proporção de pessoas qualificadas no município. Como forma de captar essa influência, são incluídas no modelo as variáveis grau de urbanização e participação relativa em números de trabalhadores dos setores secundário e terciário. A variável para o setor primário foi a omitida.

Um último ponto que provoca impacto na distribuição de indivíduos qualificados em determinado local é a localização desse com relação a outros centros urbanos. A distância entre o município e a capital do Estado também é incluída no modelo.

Resta saber se, depois de controlados os efeitos dessas variáveis citadas, o índice de entretenimento, variável também incluída no modelo, apresenta correlação significativa com a distribuição de indivíduos qualificados. 
Os resultados obtidos para os quatro modelos são mostrados na Tabela 8. Observa-se que, como as variáveis dependentes têm dimensões muito distintas, os coeficientes obtidos também possuem magnitudes diferentes.

A variável logaritmo da população do município teve um coeficiente positivo e significativo em todas elas, assim como a dummy de capital e o grau de urbanização. Isso indica que, mesmo controlando pelas demais variáveis, municípios com maior população - que são capitais de Estado e com maior grau de urbanização tinham valores mais elevados para os quatro indicadores de qualificação analisados.

Os coeficientes para as dummies de região, todos positivos e significativos, mostram que os municípios do Sul, Sudeste e Centro-Oeste tendem a apresentar valores superiores para os quatro indicadores, quando comparados com o Nordeste. Para a região Norte, três coeficientes são positivos para a proporção de trabalhadores na economia criativa, para esse indicador ajustado e para o índice síntese ajustado, sendo que o contrário ocorreu para o índice de qualificação superior. Além disso, os coeficientes obtidos para a região Norte apresentam valores muito menores, em termos de magnitude, do que os obtidos para as demais regiões, indicando uma maior homogeneidade do Norte e do Nordeste.

A variável da distância mostra que locais mais distantes das capitais, uma vez incluídas as demais variáveis, tendiam a apresentar valores maiores para as quatro variáveis.

São duas as variáveis referentes aos setores da economia: uma para o setor secundário e outra para o terciário. Para o setor secundário, os coeficientes são positivos para três das variáveis e não-significativo para o índice de qualificação superior. A variável referente ao setor terciário mostra coeficientes positivos para os quatro modelos. Assim, de forma geral, mesmo após a inclusão das demais variáveis no modelo, uma economia com maior participação dos setores mais modernos tende a apresentar maiores proporções de indivíduos qualificados.
Essas variáveis indicam a correlação entre os diversos fatores geográficos e econômicos com a distribuição de indivíduos qualificados. Com relação ao índice de entretenimento, como previu Florida (2005), ele apresenta um coeficiente positivo e significativo para o modelo com a proporção de trabalhadores na economia criativa. Assim, esse resultado inicial parece corroborar o proposto pelo autor.

Todavia, deve-se ressaltar que as ocupações de entretenimento, mesmo em proporções pequenas, fazem parte dessa variável dependente. Existe, portanto, um problema de endogenia dos dados. Para o segundo modelo, aquele que conta com o índice de qualificação superior onde esse problema não existe, o coeficiente foi nãosignificativo.

Como forma de sobrepujar essas limitações, são incluídos os dois últimos modelos deste primeiro grupo de regressões. Esses modelos utilizam, como variável dependente, a proporção ajustada de trabalhadores na economia criativa e o índice síntese ajustado. O problema de endogenia na variável proporção de trabalhadores na economia criativa e também no índice síntese é resolvido retirando, entre os trabaIhadores da economia criativa, aqueles que estavam em ocupações de entretenimento. Assim, com esse novo número, é obtida a proporção ajustada de trabalhadores na economia criativa e, com essa proporção, é calculado o índice síntese ajustado.

Depois de feitos esses ajustes, observa-se que os coeficientes para o índice de entretenimento são negativos e significativos para ambos os modelos. Ou seja, a hipótese de Florida não é corroborada para observações sem problemas de endogenia.

As variáveis de qualificação como utilizadas aqui tratam do estoque de indivíduos no município e não de fluxos. No segundo grupo de regressões, são utilizadas medidas de fluxo de indivíduos, que são estimadas a partir do saldo migratório geral e somente para indivíduos qualificados. Como calculado aqui, o saldo migratório é a diferença entre imigrantes e emigrantes para cada um dos municípios entre 1995 e 2000, 
TABELA 8

Regressões múltiplas MQO

Brasil - 2000

\begin{tabular}{lcccc}
\hline & \multicolumn{3}{c}{ Variáveis dependentes } \\
\cline { 2 - 5 } Variáveis explicativas & $\begin{array}{c}\text { Proporção de } \\
\text { trabalhadores } \\
\text { na economia } \\
\text { criativa }\end{array}$ & $\begin{array}{c}\text { Proporção } \\
\text { índice de } \\
\text { qualificação } \\
\text { superior }\end{array}$ & $\begin{array}{c}\text { Coeficientes de } \\
\text { trabalhadores } \\
\text { na economia } \\
\text { criativa }\end{array}$ & $\begin{array}{c}\text { Índice síntese } \\
\text { ajustado }\end{array}$ \\
\cline { 2 - 5 } Constante & $-2,57$ & $-3,08$ & $-2,57$ & $-0,132$ \\
População (em milhão) & 0,11 & 0,21 & 0,11 & 0,010 \\
Capital & 5,23 & 2,67 & 5,23 & 0,144 \\
Grau de urbanização (\%) & 0,86 & 0,91 & 0,86 & 0,020 \\
Região Norte & 0,58 & $-0,21$ & 0,58 & 0,005 \\
Região Sudeste & 1,56 & 1,17 & 1,56 & 0,043 \\
Região Sul & 1,99 & 1,19 & 1,99 & 0,047 \\
Região Centro-Oeste & 2,24 & 0,31 & 2,24 & 0,027 \\
Distância até a capital (1000 Km) & 1,10 & 0,68 & 1,10 & 0,024 \\
Setor secundário & 0,03 & $(1) 0,00$ & 0,03 & 0,000 \\
Setor terciário & 0,11 & 0,02 & 0,11 & 0,002 \\
Índice de entretenimento & 0,91 & $(1) 0,00$ & $-0,09$ & $-0,001$ \\
R $^{2}$ ajustado & 0,65 & 0,57 & 0,60 & 0,60 \\
\hline
\end{tabular}

Fonte: IBGE. Censo Demográfico, 2000. Dados trabalhados.

(1) Variáveis não são significativas em $5 \%$.

TABELA 9

Regressões múltiplas MQO Brasil - 2000

\begin{tabular}{|c|c|c|c|c|}
\hline \multirow{3}{*}{ Variáveis explicativas } & \multicolumn{4}{|c|}{ Variáveis dependentes } \\
\hline & \multicolumn{2}{|c|}{ Saldo migratório/população } & \multicolumn{2}{|c|}{$\begin{array}{l}\text { Saldo migratório de qualificados/ } \\
\text { população }\end{array}$} \\
\hline & \multicolumn{4}{|c|}{ Coeficientes } \\
\hline Índice de entretenimento & (1) 0,868 & (1) 0,606 & (1) 0,032 & (1) 0,027 \\
\hline Renda per capita & 0,221 & - & 0,05 & - \\
\hline Inclusão de variáveis regionais & Sim & Sim & Sim & Sim \\
\hline $\mathrm{R}^{2}$ ajustado & 0,139 & 0,122 & 0,048 & 0,043 \\
\hline
\end{tabular}

Fonte: IBGE. Censo Demográfico, 2000. Dados trabalhados.

(1) Variáveis não são significativas em $5 \%$.

calculados a partir do quesito data-fixa para migrantes internos com município de origem bem definidos. ${ }^{4}$ Os indivíduos qualificados são aqueles com 15 anos ou mais de estudo. Os valores de saldo migratório foram divididos pela população observada do município em 2000.

Foram ajustados dois modelos distintos para cada um dos tipos de saldo migratório relativo. Um contava com as mesmas variáveis acima (resultados não mostrados), com exceção da variável de população, que faz parte da variável dependente. O outro incluía também a renda per capita municipal em 1991, renda anterior à migração do indivíduo. Observa-se que os coeficientes para essa última variável são positivos e significativos para os dois tipos de saldo. Os resultados obtidos para os coeficientes referentes ao índice de entretenimento foram todos não-significativos, como mostrado na Tabela 9, indicando que, também a partir de variáveis de fluxo, a hipótese de Florida não é corroborada para os municípios brasileiros.

\footnotetext{
4 Ver Golgher (2004), para uma discussão geral sobre migração, e Golgher (2006a), para discussões sobre migração entre os municípios brasileiros.
} 


\section{Conclusão}

O ponto de partida deste texto é a relação entre a concentração de pessoas qualificadas e criativas e o desenvolvimento de cidades e regiões. Tendo como base teórica o proposto por Florida (2002a, 2002b, 2005), que discute a importância de uma sociedade vibrante na atração de talentos, é feita uma análise empírica para - Brasil sobre a distribuição de indivíduos qualificados, incluindo discussões sobre alguns dos aspectos que influenciam essa distribuição. Para tanto, são confeccionados vários indicadores, muitos baseados na metodologia utilizada por esse autor, além de vários outros distintos. Esses indicadores são: proporção de trabalhadores no setor criativo; índice de qualificação superior; índice de qualificação de pós-graduação; índice de qualificação técnica superior; índice de qualificação técnica de pós-graduação; índice síntese; índice de alta tecnologia bruto; índice de alta tecnologia relativo; e índice de entretenimento.

Alguns municípios destacam-se com os valores mais elevados para diversos indicadores, tais como: dois localizados nas RMSP e RMRJ - São Caetano do Sul (SP)

\section{Referências bibliográficas}

FLORIDA, R. The economic geography of talent. Annals of the Association of American Geographers, 92, 4, p. 743-755, 2002a.

Bohemia and economic geography. Journal of Economic Geography, 2, p. 55$71,2002 b$.

Routledge, 2005.

\section{Cities and the creative class.}

FLORIDA, R.; TINAGLI, I. Europe in the creative age, 2004. Disponível em: <http:// creativeclass.org/acrobat/Europe_in_the Creative_Age_2004.pdf $>$. Acesso em: $1 \overline{5}$ maio 2006.

GOLGHER, A. Fundamentos da migração. Belo Horizonte, Cedeplar/Face/UFMG, 2004 (Texto para discussão no 231). Disponível em: <http://www.cedeplar.ufmg.br/pesquisas/ e Niterói (RJ) -; as capitais das regiões Sul e Sudeste - Belo Horizonte (MG), Curitiba (PR), Florianópolis (SC), Porto Alegre (RS), Rio de Janeiro (RJ), São Paulo (SP) e Vitória (ES) -; e municípios de porte médio/grande destas duas macrorregiões - Campinas (SP), Ribeirão Preto (SP), Santos (SP), São Carlos (SP) e Viçosa (MG).

As análises econométricas indicam que municípios com populações maiores, que são capitais de Estado, mais urbanizados, localizados nas regiões Sul, Sudeste e Centro-Oeste e com maiores proporções dos setores secundário e terciário tendem a apresentar valores mais elevados para qualificação e criatividade, como definido por Florida (2002a, 2002b, 2005).

Segundo esse autor, regiões com maior índice de entretenimento tendem a ter maiores proporções de trabalhadores na economia criativa ou índices de qualificação. Essa hipótese não foi corroborada pelas análises empreendidas aqui tanto para estoque de pessoas qualificadas, medido pelos indicadores acima, como para fluxos de indivíduos, estimado a partir de saldos migratórios relativos obtidos por técnicas diretas.

td/TD\%20231.pdf> . Acesso em: 15 maio 2007.

Diagnóstico do processo migra-

tório no Brasil 4: migração entre municípios. Belo Horizonte, Cedeplar/Face/UFMG, 2006a (Texto para discussão no 285). Disponível em: <http://www.cedeplar.ufmg.br/pesquisas/ td/TD\%20285.pdf > . Acesso em: 15 maio 2007.

As cidades e a classe criativa no

Brasil: diferenças espaciais na distribuição de indivíduos qualificados. Belo Horizonte, Cedeplar/Face/UFMG, 2006b (Texto para discussão no 296). Disponível em: <http:// www.cedeplar.ufmg.br/pesquisas/td/TD\%20 296. pdf > . Acesso em: 15 maio 2007.

IBGE - Instituto Brasileiro de Geografia e Estatística. Censo Demográfico de 2000. Rio de Janeiro, 2000. 
JACOBS, J. Morte e vida das grandes cidades. São Paulo: Matins Fontes, 2001.

NEW ENGLAND COUNCIL. The creative economy initiative: the role of the arts and culture in New England's economic competitiveness. Boston: New England Council, July, 2000.

NEARY, J. Of hype and hyperbolas: introducing the new economic geography.
Journal of Economic Literature, 39, p. 536-561, 2001.

SCOTT, A. A perspective of economic geography. Journal of Economic Geography, 4, p. 479-499, 2004.

HAIR, J.; ANDERSON, R.; TATHAN, R.; BLACK, W. Análise multivariada de dados.

5 ed. Porto Alegre: Bookman, 2006

\section{Resumen}

Las ciudades y la clase creativa en Brasil: diferencias espaciales en la distribución de individuos cualificados en los municipios brasileños

Partiendo de la premisa que los estudios regionales deben incorporar aspectos económicos y culturales conjuntamente y teniendo como base empírica los indicadores propuestos por Florida, son confeccionados varios indicadores relacionados a la distribución de individuos cualificados en los municipios brasileños. Análisis descriptivos y la utilización de la técnica multivariada de aglomerados muestran que algunos municipios se destacan con valores más elevados para diversos indicadores, tales como: São Caetano do Sul (SP), Niterói (RJ) y Florianópolis (SC). Estudios econométricos indican que municipios con mayor población, que son capitales de estado, más urbanizados, localizados en las regiones Sur, Sudeste o CentroOeste y con mayor participación del sector secundario y del terciario en la economía, tienden a tener mayores proporciones de trabajadores en la economía creativa, o mayores índices de cualificación. La hipótesis de Florida, que propone que lugares con ambiente más estimulante también presentan esa tendencia, no fue corroborada por estos estudios.

Palabras-clave: Florida. Indicadores de cualificación.

\section{Abstract \\ Cities and creative class in Brazil: spatial differences in the distribution of qualified individuals in Brazilian municipalities}

Based on the idea that regional studies should be addressed jointly through economic and cultural aspects, and based empirically on indicators proposed by Florida, numerous indicators of the distribution of qualified individuals were used to compare municipalities in Brazil. Cluster and descriptive analyses showed that some municipalities showed higher values for a number of indicators, including São Caetano do Sul (SP), Niterói (RJ) and Florianópolis (SC). Econometric analyses indicated that more urbanized municipalities with larger populations, located in the southern, southeastern and center-western regions, and with larger industrial and services sectors, tend to show higher proportions of workers in the creative economy or who show higher indicators of qualified individuals. Florida's hypothesis, which suggests that municipalities with more vibrant atmospheres also concentrate this type of individuals, was not corroborated by these studies.

Keywords: Florida. Qualification indicators. 